\title{
Research
}

\section{The Interest of Women Medical Students in Urology. The Major Deterrents!}

\author{
Kashif Bangash ${ }^{1}$, Faria Mumtaz ${ }^{2}$, Hassan Mumtaz ${ }^{3^{*}}$, Khursheed Anwar ${ }^{4}$, Shahzaib Ahmad , Farrukh Zaman $^{6}$ \\ ${ }^{1}$ Assisstant Professor of Urology, Fazaia Medical College, Pakistan \\ ${ }^{2}$ Post Graduate Trainee, Nescom Hospital, Pakistan \\ ${ }^{3}$ House Surgeon, KRL Hospital, Pakistan \\ ${ }^{4}$ Professor of Urology, PAEC General Hospital, Pakistan \\ ${ }^{5}$ Medical Student, King Edward Medical University Lahore, Pakistan \\ ${ }^{6}$ Consultant Medicine, KRL Hospital, Pakistan
}

^Correspondence to: Hassan Mumtaz; House Surgeon, KRL Hospital, Pakistan; E-mail: Hassanmumtaz.dr@gmail.com

Received: Jan 5 ${ }^{\text {th }}, 2021$; Accepted: Jan 13 ${ }^{\text {th }}, 2020$; Published: Jan 15 $5^{\text {th }}, 2021$

Citation: Bangash K, Mumtaz F, Mumtaz $\mathrm{H}^{\star}$, Anwar K, Ahmad S, Zaman F. The interest of women medical students in urology. The major deterrents!. Urology Open A Open J. 2021; 2(1): 50-53. doi: 10.33169/uro.UOAOJ-2-113

\begin{abstract}
Introduction: The medical profession was formerly a male-dominated one, but over the years, the population of female medical students has risen. The representation of women in surgery and allied specialities has always been a debate accross the world. Like most surgical fields, Urology remains a male dominant profession. A critical component of the advancement of any field is the reqruitment of the brightest medical students of both genders. To improve the distaff workforce, it is important to understand why qualified students would not enter the field.
\end{abstract}

Objectives \& Methodology: A total of 218 questionnaires were filled. 94 from final year students, and 124 house officers and postgraduate female doctors. The respondents were asked to choose the most appropriate response and choices among the options listed and were allowed to choose at least one but not more than three options.

Results: Out of 218 females, only $26 \%$ choose to opt a career in urology, where as $74 \%$ females had a clear answer that was NO. Those who wished to join surgery considered stress during the working hours (47.8\%), lifestyle and family concerns (45.7\%), and interest that developed during the medical graduation (35.7\%) as strong determinants. Male dominance in the field (47.8\%), "do not want to operate on the genitals" (45.6\%), and cultural issues (29.1\%) to be the most deterring factors.

Discussion: The choice of specialty by medical students is a complex process involving a myriad of variables. Lifestyle and family concerns have been the most important determining factor for choice in any surgical field (urology career 5), 45.7\% in our study, which is consistent with other studies across the world, but surprisingly $15.9 \%$ of respondents cited lifestyle as a negative factor in choosing the field. The more concerning factors that refrain the final year students to enter the field as compared to house officers and postgraduate residents were lack of interest, poor lifestyle, and high work stress in the field. Adequate clinical exposure to urology enables medical students to build a rational perception of the field. The decision making can be unbiased only when it is not influenced by myths related to urology and other specializations.

\section{Conclusion}

It is important to develop a realistic perception of urological field that includes female urology as well. It should be ensured that medical students have clinical exposure to urology, receiving appropriate mentorship, and develop a curriculam of the specialty during undergraduate program that may substantially facilitate recruitment.

Keywords: Female Urology; Women; Clinical practice; Urology. 


\section{INTRODUCTION}

The medical profession was formerly a male-dominated one, but over the years, the population of female medical students has risen. Now women comprise almost half of the students entering the medical colleges in the country. ${ }^{1}$ Similarly, it is conceded that the number of women entering the surgical specialties is rising, but the rate is still slower than expected. In America, despite the fact that half of the medical schools are comprised of women, less than $5 \%$ enter the surgical sub-specialties. ${ }^{2}$

The representation of women in surgery and allied specialties has always been a debate across the world. Many convincing studies have proved the various factors that affect the choice of women for a career in surgery. Some have found that lifestyle consideration and women friendliness were most important to women. ${ }^{3}$ With some concluding that dominant male culture in surgery and perception of surgery as "old boys' club" was important sex-specific deterrents. ${ }^{4}$

Like most surgical fields, urology remains a male dominant profession. ${ }^{5}$ Little research has been done to assess the determinants of medical students' selection of urology as a career. ${ }^{6}$

To date, there are only few female urologists \& urology residents present in Pakistan. ${ }^{7}$ No work has been done to assess the factors that pull the distaff medical students to join the field.

This project aims to discover the deterrents for a female to a career in urology and what challenges related to their gender they think they might face during the training period. And by knowing this, we might be able to raise the proportion of female urologists in Pakistan.

\section{METHODS}

The female students of final year, female doctors working as House Officers (HO) and as Post-Graduation Trainees (PGT) in any field were evaluated through a questionnaire. A total of 218 questionnaires were filled by the medical students of different colleges and hospitals of Islamabad and Rawalpindi. 94 from final year students and 124 house officers and postgraduate female doctors. The respondents were asked to choose the most appropriate response and choices among the options listed and were allowed to choose at least one but not more than three options. Several questions were directed only to medical students. All data were imported to SPSS version 20 for frequency and percentages.

\section{RESULTS}

Out of 218 females, only $26 \%$ choose to opt a career in urology, where as $74 \%$ females had a clear answer that was NO. Those who wished to join surgery considered stress during the working hours (47.8\%), lifestyle and family concerns (45.7\%), and interest that developed during the medical graduation (35.7\%) as strong determinants. Male dominance in the field (47.8\%), "do not want to operate on the genitals" (45.6\%), and cultural issues (29.1\%) to be the most deterring factors (Figures 1-4).
Figure 1. Those who wished to join surgery would consider stress during the working hours $(47.8 \%)$, lifestyle and family concerns $(45.7 \%)$, and interest that develops during the medical graduation (35.7\%) as strong determinants. It is important to realize that it is upon these perceptions (or misperceptions) that students make their career choices at this stage. Only $26 \%$ of the doctors had direct interaction with urologists during their medical school period

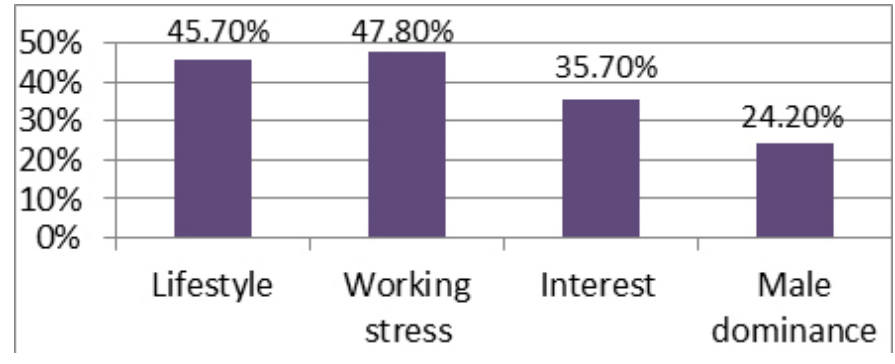

Figure 2. Out of 218 females, only $26 \%$ choose to opt a career in urology, where as $74 \%$ females had a clear answer that was NO

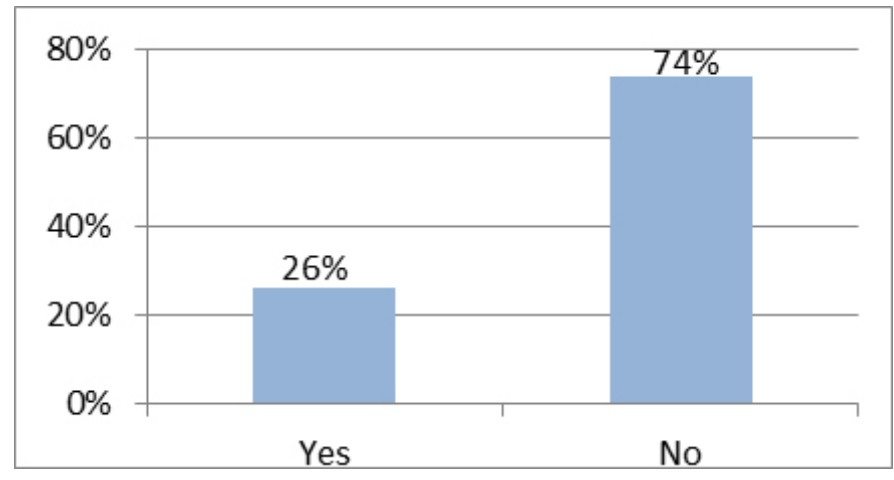

Figure 3. Discussing the lifestyle, work stress, post partum \& interest of Final Year Students, House Officers \& Residents

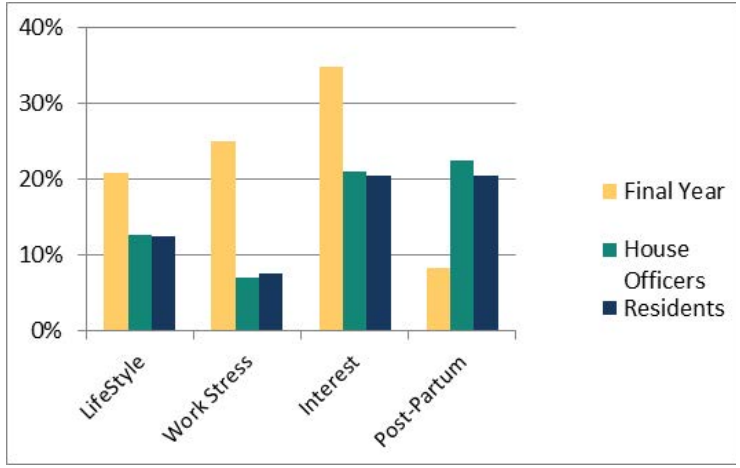

Figure 4. Male dominance in the field (47.8\%), "do not want to operate on the genitals" (45.6\%), and cultural issues $(29.1 \%)$ to be the most deterring factors

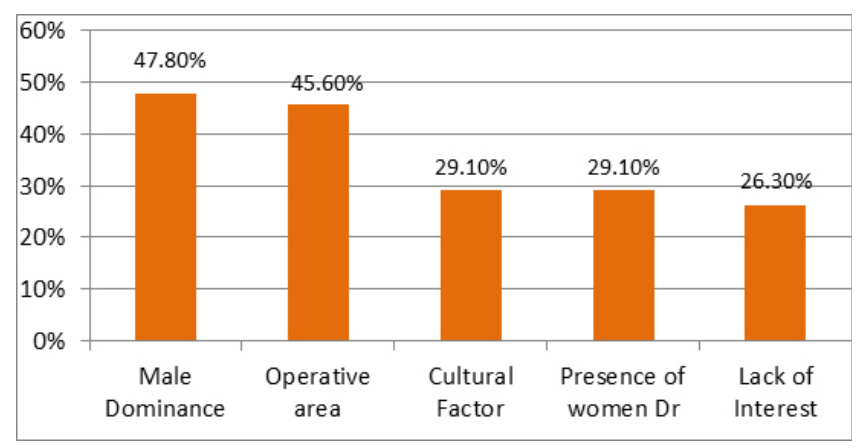




\section{DISCUSSION}

The choice of a career by a medical student is a crucial step influenced by numerous factors. Career preference and the factors affecting it remain uncertain, and literature available in this aspect is scarce. ${ }^{8}$ Hence, the choice of specialty by medical students is a complex process involving a myriad of variables, i.e., the character of the field, role models in the training program, lifestyle, gender dominancy of doctors and patients, parents advice, peer pressure, respect in the field, ease of the job, earning capacity and many more. ${ }^{9}$ The fields in medical meridian must be ornamented by competent health professionals despite their gender or other discrimination. A critical component of the advancement of any field is the recruitment of the brightest medical students of both genders. ${ }^{10}$ To improve the distaff workforce, it is important to understand why qualified students would not enter the field. ${ }^{11}$ The mystery of preference of a particular field by a specific gender needs to be resolved.

Our study revealed that in a tertiary healthcare facility in Pakistan, females are reluctant to pursue urology as the field of specialty. Furthermore, the study brought to limelight the major concerns of the female doctors in choosing urology as a career. Urology involves history, examination, and clinical methods involving hidden and private parts of the body. ${ }^{12}$ The experience of female doctors in urology is somewhat unique among the surgical specialties. It affords frequent interactions with men than are experienced by surgeons in general. ${ }^{13}$ And this interaction involves the history of Urinary Tract Infections, sexual practice, STDs, sexual partnerships, and examination of the genitalia. A female doctor may feel shy when it comes to examining the genitalia of a male patient. ${ }^{14}$ Greater interaction with the male gender maybe because of the preponderance of male patients and also doctors in the specialty. The overall outlook of a specialty has a practical significance. The general repulsion for the urology specialty prevalent in females is linked with a substantially low number of female resident trainees in the field. ${ }^{15}$ This may also lead to gender dominance within specialty training. Gender dominance in a specialty is among the strongest influencer on the preference by trainees belonging to a particular gender. ${ }^{16}$ Numerous studies illustrate similar observations. Bradbury et al. (survey of urologist) reported that $63 \%$ believed that gender discrimination affected their practice, and $44 \%$ noted they were discouraged from choosing urology because of gender. ${ }^{17}$ Urology is a field that is dominated by male physicians. Although this is beginning to change, concerns have been raised that this preponderance of male urologists may dissuade female medical students from entering the field. ${ }^{18}$

Lifestyle and family concerns have been the most important determining factor for choice in any surgical field (urology career 5), $45.7 \%$ in our study, which is consistent with other studies across the world, but surprisingly $15.9 \%$ of respondents cited lifestyle as a negative factor in choosing the field. Infact, a study by Marley (satisfaction study) showed that women urologists were moderate to highly satisfied with their career and personal lives and did not feel that their personal and/ or family lives were compromised..$^{15}$ Likewise, work-stress with tough on-call duties were important deterrents to any surgical specialty by the female doctors, but relating to urology, ${ }^{19}$ it was not greatly influenced the choice which was in the present study.

Critically analyzing the results, the more concerning factors that refrain the final year students to enter the field as compared to house officers and postgraduate residents were lack of interest, poor lifestyle, and high work stress in the field. ${ }^{20}$ These perceptions might be due to a lack of familiarity with the field, probably due to short clinical exposure during medical education. ${ }^{21}$ However, the characterizations like poor lifestyle as a urologist and greater workload might not be correct. In a survey conducted in the United Kingdom, 28\% of urologists stated that their specialty decision was influenced by their undergraduate (medical school) exposure to urology. Their top four reasons for selecting urology as a career were 1) inspirational role models, 2) exposure to urology as a house officer, 3) variety of open and endoscopic urological procedures, 4) the quiet on-calls and sociable lifestyle 5) science Uk Para. ${ }^{22}$ Ironically in our study, only $26 \%$ of the students had direct interaction with the urologist. It is crucial to ensure adequate exposure to urology at the undergraduate level and that students develop a realistic view as to what a career in urology entails. ${ }^{23}$

Adequate clinical exposure to urology enables medical students to build a rational perception of the field. The decision making can be unbiased only when it is not influenced by myths related to urology and other specializations. ${ }^{12,14}$

\section{CONCLUSION}

Career choice is a cumbersome task for male and female medical students alike. But, the efflux of female undergraduates towards urology is substantially low. To recruit female medical students, it is important to help the students to develop a realistic perception of the urological field that includes female urology as well.

Ensuring that medical students have clinical exposure to urology, receive appropriate mentorship, and develop curricula of the specialty during the undergraduate program may substantially facilitate recruitment.

\section{CONFLICTS OF INTEREST}

\section{None.}

\section{REFERENCES}

1. Anis Rehman, Tariq Rehman, Muhammad Ateeb Shaikh, Haleema Yasmin, Ammara Asif, Hina Kafil. Pakistani Medical Students' Specialty Preference and The Influencing Factors. J Pak Med Assoc. 2011; 61(7): 713-718.

2. Laura J Linscheid, Emma B Holliday, Awad Ahmed, Jeremy S Somerson, Summer Hanson, Reshma Jagsi, et al. Women in Academic Surgery Over The Last Four Decades. 2020; 15(12): e0243308. doi: 10.1371/ journal.pone. 0243308

3. Peel JK, Schlachta CM, Alkhamesi NA. A Systematic Review of The Factors Affecting Choice Of Surgery as A Career. Can J Surg. 2018; 61(1): 58-67. doi: 10.1503/cjs.008217

4. IH Marks, A Diaz, M Keem, Seyedeh-Sanam Ladi-Seyedian, GS. Philipo, H Munir, et al. Barriers to Women Entering Surgical Careers: A Global Study into Medical Student Perceptions. World J Surg . 2019; 44: 37-44. doi: 10.1007/s00268-019-05199-1

5. These Medical Specialties Have The Biggest Gender Imbalances. Website: https://www.ama-assn.org/residents-students/specialty-profiles/these-medical-specialties-have-biggest-gender-imbalances

6. Kerfoot B, Nabha Kate, Masser, David L. Mccullough. What Makes a Medical Student Avoid or Enter a Career in Urology? Results of an International Survey. The Journal of urology. 2005; 174(5): 1953-1957. doi: 10.1097/01.ju.0000177462.61257.4e 
7. Ather MH, Siddiqui T. Urology Training in The Developing world: The trainers' Perspective. Arab J Urol. 2014; 12(1): 64-67. doi: 10.1016/j. aju.2013.07.001

8. Gargiulo DA, Hyman NH, Hebert JC. Women in Surgery: Do We Really Understand The Deterrents? Arch Surg. 2006; 141(4): 405-407. doi: 10.1001/archsurg.141.4.405

9. Marley CS, Lerner LB, Panagopoulos G, Elizabeth Kavaler. Personal, Professional and Financial Satisfaction among American Women Urologists. Int Braz J Urol. 2011; 37(2): 187-189. doi: 10.1590/s167755382011000200005

10. Moller MG, Karamichalis J, Chokshi N, Haytham Kaafarani, Heena P Santry. Mentoring the Modern Surgeon. Bull Am Coll Surg. 2008; 93(7): $19-25$.

11. Lightner DJ, Terris MK, Tsao AK, Cathy K Naughton, Christine M Lohse. Status of Women In Urology: Based on A Report to The Society of University Urologists. J Urol. 2005; 173(2): 560-563. doi 10.1097/01. ju.0000149739.51103.d3

12. Oberlin DT, Vo AX, Bachrach L, Sarah C Flury. The Gender Divide: The Impact Of Surgeon Gender On Surgical Practice Patterns in Urology. J Urol.2016; 196(5): 1522-1526. doi: 10.1016/j.juro.2016.05.030

13. Jackson I, Bobbin M, Jordan M, Stephen Baker. A Survey of Women Urology Residents Regarding Career Choice and Practice Challenges. J Womens Health (Larchmt). 2009; 18(11): 1867-1872. doi: 10.1089/ jwh.2008.1236

14. Spencer ES, Deal AM, Pruthi NR, Chris M Gonzalez, E Will Kirby, Joshua Langston, et al. Gender Differences in Compensation, Job Satisfaction and Other Practice Patterns In Urology. J Urol. 2016; 195(2): 450-455. doi: 10.1016/j.juro.2015.08.100

15. Mayer EN, Lenherr SM, Hanson HA, Terry C Jessop, William T Lowrance. Gender Differences in Publication Productivity Among Aca- demic Urologists in The United States. Urology. 2017; 103: 39-46. doi: 10.1016/j.urology.2016.12.064

16. Cancian M, Aguiar L, Thavaseelan S. The Representation of Women In Urological Leadership. Urology Practice. 2018; 5(3): 228-232. doi: 10.1016/j.urpr.2017.03.006

17. Velez D, Ashok A, Greenberg R, Meredith Wasserman, Alejandra Balen, Jennifer Fantasia, et al. Rising Tides: Challenges and Opportunities for Women in the Urologic Workforce. Urology . 2020; S00904295(20): 30870-0. doi: 10.1016/j.urology.2020.07.014

18. Anderson K, Tennankore K, Cox A. Trends in The Training of Female Urology Residents in Canada. Canadian Urological Association Journal. 2018; 12(3): E105. doi: 10.5489/cuaj.4697

19. Dai JC, Agochukwu-Mmonu N, Hittelman AB. Strategies For Attracting Women and Underrepresented Minorities in Urology. Curr Urol Rep. 2019; 20(10): 61. doi: 10.1007/s11934-019-0921-5

20. Porten SP, Gaither TW, Greene KL, Nima Baradaran, Jennifer T Anger, Benjamin N Breyer. Do Women Work Less Than Men In Urology: Data From The American Urological Association Census. Urology. 2018; 118: 71-75. doi: 10.1016/j.urology.2018.04.015

21. Johns Putra L, Cheng J, Dowling C, Anita Clarke. Practice Patterns of Female Urologists In Australia And New Zealand. BJU international. 2018; 122: 9-14. doi: 10.1111/bju.14407

22. Cocci A, Patruno G, Gandaglia G, Principi E, Talso M, Baldesi R, et al. Urology Residency Training In Italy: Results of The First National Survey. Eur Urol Focus. 2018; 4(2): 280-287. doi: 10.1016/j. euf.2016.06.006

23. Saltzman A, Hebert K, Prats S, Ashley Richman, Joanna Togami, Leslie Rickey, et al. Women urologists: Trends in Mentoring and Career Choices. Urology practice. 2016 ; 3(4): 302-308. doi: 10.1016/j. urpr.2016.01.005 